\title{
Commitment of protein p53 and amyloid-beta peptide (A $\beta)$ in aging of human cerebellum
}

\author{
Danuta Maślińska ${ }^{1,2}$, Milena Laure-Kamionowska ${ }^{2}$, Dariusz Szukiewicz ${ }^{1}$, Sławomir Maśliński ${ }^{1}$, \\ Krystyna Księżopolska-Orłowska ${ }^{3}$
}

\begin{abstract}
${ }^{1}$ Department of General and Experimental Pathology, Warsaw Medical University, Warsaw, ${ }^{2}$ Department of Experimental and Clinical Neuropathology, Mossakowski Medical Research Centre, Polish Academy of Sciences, Warsaw, ${ }^{3}$ Department of Rehabilitation, National Institute of Geriatrics, Rheumatology and Rehabilitation, Warsaw, Poland
\end{abstract}

\begin{abstract}
Protein p53 is known to induce the cell cycle arrest and apoptosis in response to a variety of cellular distress signals and DNA damage. A recent study has demonstrated that in blood cells of aging subjects, $p 53$ may induce early pathological changes that precede the amyloidogenic cascade. However, it is not clear whether p53 participates in the local deposition of amyloid-beta peptide $(A \beta)$ in the nerve tissue of normal aging subjects. Therefore, in the present study, we analyse the distribution of both (A $\beta$ and $p 53)$ proteins in the cerebellum of individuals without any history of dementia or other neurological illness who died suddenly in traffic accidents.

We found that in the subjects at the beginning of their aging process (60-65 years of age) $A \beta$ deposits were localized in subependymal areas of the cerebellar cortex and such deposits were not linked to the presence of $p 53$ in the nerve tissue. In groups of subjects over 65 years of age, numerous $A \beta$ diffuse plaques were scattered throughout the cerebellar cortex. In these subjects, $p 53$ protein was detected in the cytoplasm or in the nucleus of the cerebellar nerve cells.

All the results lead to the conclusion that in nerve tissue 553 participates in the process of neurodegeneration and then it is involved in the deposition of $A \beta$ in the nerve tissue.
\end{abstract}

Key words: amyloid-beta $(A \beta)$ deposits, aging, cerebellum, p53, neurodegeneration.

\section{Introduction}

The brain as any other organ shows morphological changes with the increasing age. In humans, most prominent morphological features of the brain aging include extracellular deposits of amyloid and intracellular neurofibrillary tangles. Amyloid deposits may take a form of diffuse, neuritic or senile plaques and angiopathy in small blood vessels. The main component of such deposits is beta-amyloid (A $\beta)$ which is a fragment of the amyloid precursor protein (APP) snipped from APP during its metabolism.

Clinical symptoms at the beginning of human aging are characterized by a decrease in muscle strength, impairment of vision, and diminution of hearing but progress of aging leads to the further symptoms such as loss of memory for recent events, decreased abstract thinking, disorientation and dementia including Alzheimer's disease (AD). 
Currently, with the increasing life expectancy across the world, problems inherent in aging are the focus of the intensive study. A substantial body of evidence suggests that the lifespan is under genetic control but decades of quest for human longevity genes were not successful. Results of the studies suggest that the epigenetic mechanisms probably play a role in modulating the lifespan $[13,23,34]$. Moreover, these studies document that the heritability of epigenetic age acceleration in various brain regions is different and that the heritability of age acceleration of the cerebellum appears to be higher than that of the frontal cortex, pons or temporal cortex.

The role of the cerebellum in motor coordination of the body movement is well known $[8,11,35]$ but increasing evidence shows that the cerebellum plays also a significant role in cognitive functions such as attention, language, emotional behaviour, sleep, and even non-somatic visceral responses [21,29].

A distinct functional topography for the cerebellum has been shown, reflecting connections to distributed circuits within the central nervous system (CNS) $[31,32]$. These include loops associated with cognitive processing where the cerebellum exerts a modulating effect that may be impaired in neuropsychiatric diseases [20,24-27].

Coupling within various neural networks and brain systems is known to be affected by amyloid pathology in $A D[4,6,18,28]$, but also in elderly subjects with normal cognitive performance effects of brain amyloidosis on functional integrity of the cerebro-cerebellar system has been documented [2]. Moreover, brain amyloidosis-related changes in cerebro-cerebellar coupling indicate brain regions with particular vulnerability to amyloid-associated pathology $[29,30]$.

For the last few decades, the prevention and treatment of the cognitive disorders including $A D$ has remained a major challenge for clinicians and scientists. In view of existing and emerging therapeutic compounds, the focus has increasingly shifted to accurate detection of the earliest phase of the illness. Results of performed studies with a wide variety of different proteins such as inflammatory markers, markers of oxidative stress, apolipoproteins, and markers of neuronal degeneration suggest $[3,36]$ that the measurement of conformational altered p53 in blood cells has a high ability to early discriminate AD cases from normal aging [14]. It was also observed that such defective $p 53$ when influenced by very low concentrations of soluble $A \beta$, may induce at a cellu- lar level, early pathological changes that precede the amyloidogenic cascade.

A recent study has demonstrated that $A \beta$ is linked to functional reorganization within the cerebrocerebellar system, taking place in elderly individuals with normal cognitive performance. However, it is not clear whether p53 protein participates in local deposition of $A \beta$ in cerebellar of normal aging subjects as it was observed in the cells of peripheral tissues. Therefore, in the present study, we analyse the distribution of both proteins in the cerebellum of individuals without any history of dementia or other neurological illness and who died suddenly in traffic accidents.

\section{Material and methods}

The study was performed performed on archival material of brain sections collected routinely at autopsies. All subjects were victims of traffic accidents in which they participated as drivers or as pedestrians. Paraffin blocks were drawn from the files of the Mossakowski Medical Research Centre, Polish Academy of Sciences, Warsaw, Poland. Serial sections $5 \mu \mathrm{m}$ thick were stained with H\&E for routine histological examination or used for immuno-histochemical study.

Immunohistochemistry was performed using specific primary antibodies:

- monoclonal mouse anti-human p53 protein Clone DO-7 Code No. M 7001 Lot 075 was purchased from DAKO and supplied in liquid form as tissue culture supernatant (RPMI 1640 medium containing foetal calf serum) dialysed against $0.05 \mathrm{M}$ Tris/ $\mathrm{HCl}, \mathrm{pH} 7.2$ containing $15 \mathrm{mM} \mathrm{NaN}_{3}$. The DAKO antibody recognizes an epitope in the $\mathrm{N}$-terminus of the human p53 protein. The epitope for the antibody is known to be residing between amino acids 19 to 26;

- monoclonal mouse anti- $\beta$-amyloid 4G8 which recognizes an epitope residing between amino acids 17-24 of $A \beta$ protein was purchased from BioLegend;

- polyclonal rabbit anti- $\beta$-amyloid which recognizes an epitope residing between amino acids 1-42 protein of $A \beta$ was purchased from Bio-Rad;

- alkaline phosphatase-avidin-biotin conjugate purchased from Santa Cruz Biotechnology, Inc. (USA);

- avidin-biotin-peroxidase complex system purchased from Vector Laboratories (USA);

- and all of them were used according to the manufacturer's recommendations. 
Briefly, sections were dewaxed and hydrated through descending alcohols to water. For non-enzymatic antigen retrieval, tissue sections were heated in $0.01 \mathrm{M}$ sodium citrate buffer $(\mathrm{pH} 6.0)$ to $95^{\circ} \mathrm{C}$ and allowed to cool for $20 \mathrm{~min}$ at room temperature and washed with PBS. Then, they were incubated in a solution of methanol containing $3 \% \mathrm{H}_{2} \mathrm{O}_{2}$ for 20 min to quench endogenous peroxidase. Washed again in PBS and blocked with a solution of PBS containing 5\% appropriate normal serum (rabbit or mouse) for $2 \mathrm{~h}$ at room temperature, sections were incubated overnight at $4^{\circ} \mathrm{C}$ in solutions of the primary antibody. Immunoreactions were visualized using biotinylated secondary antibodies and ABComplex/HRP or an alkaline phosphatase-avidin-biotin conjugate. Then, sections were lightly counterstained with Mayer's haematoxylin.

For negative controls, primary antibodies were replaced with an appropriate isotypic normal mouse or rabbit immunoglobulin fraction at matched protein concentration. These were included for the examination of each specimen and consistently produced negative results.

\section{Results}

Data pertaining to the groups of drivers and pedestrians who were victims of traffic accidents are shown in Tables I and II. Amyloid $\beta$ peptide and p53 protein were found in approximately $50 \%$ of subjects. The immunoexpression and distribution of both proteins in cerebella of drivers were similar as in age-matched groups of pedestrians. In the group of subjects of 55-65 years of age, deposits of $A \beta$ in form of diffuse plaques were detected only at the most peripheral areas of the cerebellar cortex (Table I). In groups of the older subjects, such plaques were scattered throughout the molecular and Purkinje cell layers (Fig. 1). Plaques were of different size and peculiar shape (Fig. 2).

Distribution of p53 protein in the cerebellum was clearly linked with the layer of the Purkinje cells (Fig. 3).

In the youngest groups of subjects (55-65 years of age), p53 was not detected in groups of the older individuals, p53 immuno-positive grains were found only in cytoplasm of some Purkinje cells (Table II). These grains were cumulated in the cytoplasm around the nucleus of the cells (Fig. 4).

In numerous Purkinje cells and other nerve cells, p53 was detected also within the cell nucleus (Table II and Fig. 5) but never simultaneously in the nucleus and in cytoplasm of the same cell. Accumulation of p53 protein in the cell nucleus precedes the cell degeneration and death. In the double immunostained tissue

Table I. Distribution of amyloid $\beta$ deposits in the cerebellum of subjects participating in traffic accidents

\begin{tabular}{|c|c|c|c|c|c|c|c|}
\hline \multirow{2}{*}{$\begin{array}{l}\text { Groups } \\
\text { Drivers }\end{array}$} & \multirow[t]{2}{*}{ Number } & \multirow[t]{2}{*}{ Age } & \multicolumn{4}{|c|}{ Areas of cerebellar cortex } & \multirow[t]{2}{*}{ White matter } \\
\hline & & & SM & ML & PC & $\mathrm{GL}$ & \\
\hline & 7 & $55-65$ & $4 / 7$ & $0 / 7$ & $0 / 7$ & $0 / 7$ & $0 / 7$ \\
\hline & 9 & $66-75$ & $5 / 9$ & $5 / 9$ & $3 / 9$ & $0 / 9$ & $0 / 9$ \\
\hline & 5 & $76-85$ & $4 / 5$ & $4 / 5$ & $4 / 5$ & $0 / 5$ & $0 / 5$ \\
\hline \multirow[t]{3}{*}{ Pedestrians } & 8 & $55-65$ & $5 / 8$ & $0 / 8$ & $0 / 8$ & $0 / 8$ & $0 / 8$ \\
\hline & 7 & $66-75$ & $5 / 7$ & $5 / 7$ & $5 / 7$ & $0 / 7$ & $0 / 7$ \\
\hline & 6 & 76-85 & $4 / 6$ & $4 / 6$ & $4 / 6$ & $0 / 6$ & $0 / 6$ \\
\hline
\end{tabular}

$S M$ - submeningeal area of the cerebellar cortex, $P C$ - Purkinje cell layer, $M L$ - molecular layer of the cerebellar cortex (whole), GL - granular layer

Table II. Distribution of p53 protein in the cerebellum of subjects participating in traffic accidents

\begin{tabular}{|c|c|c|c|c|c|c|c|c|}
\hline \multirow{3}{*}{$\begin{array}{l}\text { Groups } \\
\text { Drivers }\end{array}$} & \multirow[t]{3}{*}{ Number } & \multirow[t]{3}{*}{ Age } & \multicolumn{6}{|c|}{ Distribution of $\mathrm{p} 53$ within the cell } \\
\hline & & & \multicolumn{3}{|c|}{ Cytoplasm } & \multicolumn{3}{|c|}{ Nucleus } \\
\hline & & & ML & PC & $\mathrm{GL}$ & $M L$ & PC & GL \\
\hline & 7 & $55-65$ & $0 / 7$ & $0 / 7$ & $0 / 7$ & $0 / 7$ & $0 / 7$ & $0 / 7$ \\
\hline & 9 & $66-75$ & $0 / 9$ & $5 / 9$ & $0 / 9$ & $0 / 9$ & $4 / 9$ & $0 / 9$ \\
\hline & 5 & $76-85$ & $0 / 5$ & $3 / 5$ & $0 / 5$ & $0 / 5$ & $4 / 5$ & $0 / 5$ \\
\hline \multirow[t]{3}{*}{ Pedestrians } & 8 & $55-65$ & $0 / 8$ & $0 / 8$ & $0 / 8$ & $0 / 8$ & $0 / 8$ & $0 / 8$ \\
\hline & 7 & $66-75$ & $0 / 7$ & $4 / 7$ & $0 / 7$ & $0 / 7$ & $4 / 7$ & $0 / 7$ \\
\hline & 6 & $76-85$ & $0 / 6$ & $3 / 6$ & $0 / 6$ & $0 / 6$ & $4 / 6$ & $0 / 6$ \\
\hline
\end{tabular}

$M L$ - molecular layer, $P C$ - Purkinje cells, GL - granular layer 


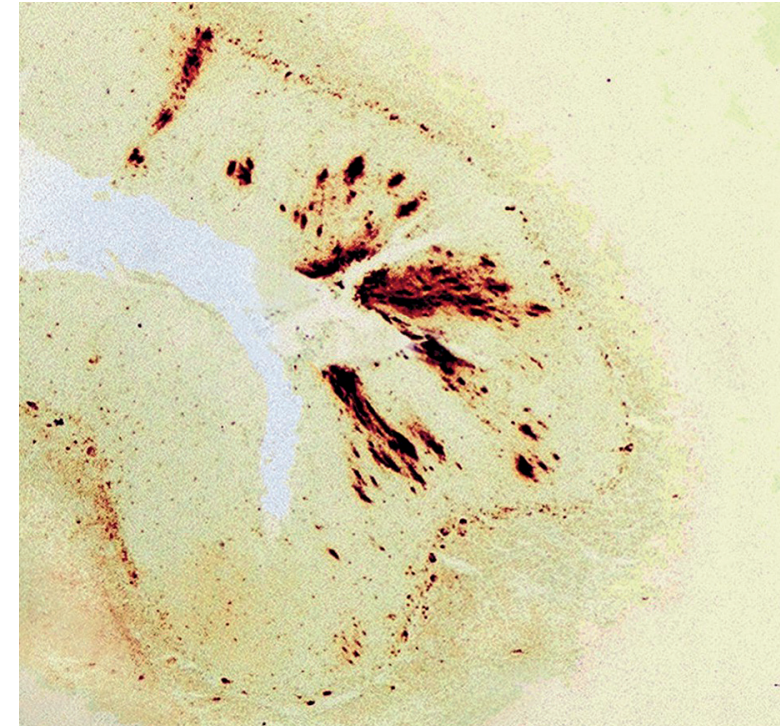

Fig. 1. Diffuse deposits of amyloid $\beta$ protein in molecular and Purkinje cell layers of the cerebellum. Pedestrian, 68 years of age. Immunoreaction visualized with avidin-biotin-peroxidase system/DAB. Magnification $\times 200$.

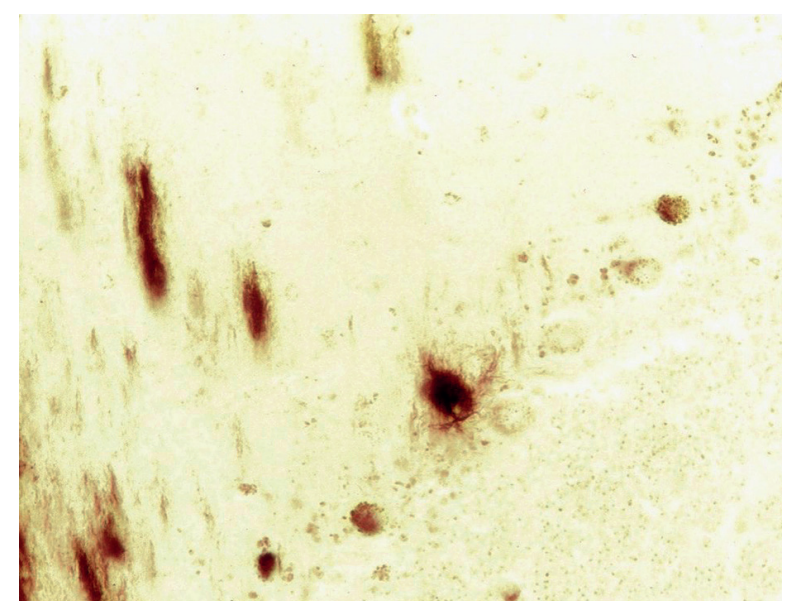

Fig. 3. Amyloid $\beta$ immunopositive fibrous material coming from degenerating nerve cells of the Purkinje cell layer of the cerebellum. Subject 72 years of age. Immunoreaction visualized with avidin-biotin-peroxidase complex system/DAB. Magnification $\times 200$.

sections, co-localization of $A \beta$ and $p 53$ in the same cells was not found.

\section{Discussion}

Cerebro-cerebellar couplings modulate the motor and cognitive functions of the human brain. In aging,

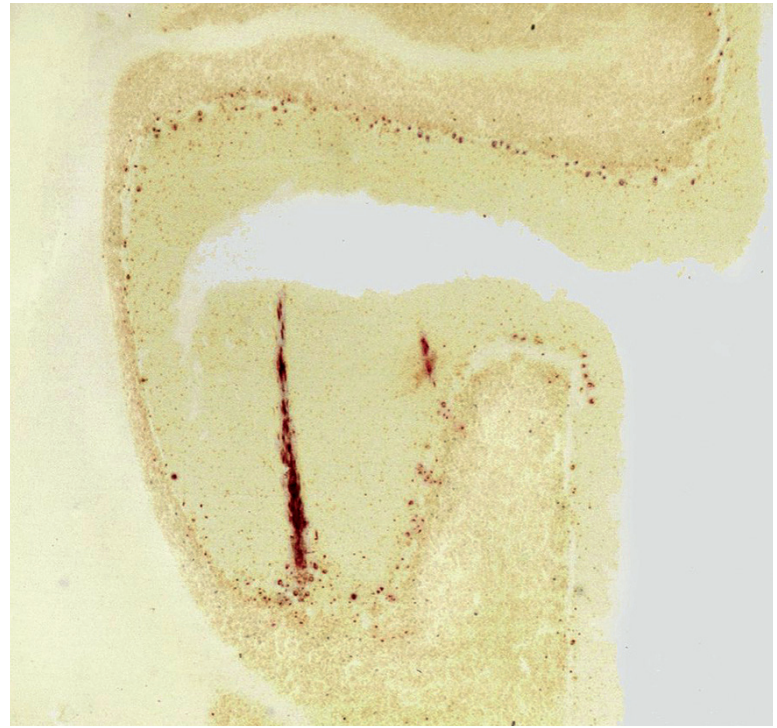

Fig. 2. Peculiar "stick-like" shape of the amyloid $\beta$ deposit in the cerebellum of the subject (driver), 72 years of age. Immunoreaction visualized with avidin-biotin-peroxidase complex/ DAB. Magnification $\times 200$.

these systems may be disordered by $A \beta$ deposits. The source of $A \beta$ is the amyloid precursor protein (APP) which is a normal structural protein of the cell membrane widely distributed throughout the body. Numerous environmental factors including the aging process, increase catabolism of APP and deliver different fragments of $A \beta$ that are quickly removed from the peripheral tissues but some of them may cumulate in cerebro-spinal fluid (CSF). Although, the brain barrier mechanisms control arrival to the CNS of different products and support the clearance of harmful metabolites, the subependymoma regions of the CNS are less controlled by such mechanisms, therefore, they may be affected by some systemic diseases including amyloidogenic processes. In the present study, amyloid deposits of such localization were found in cerebella of our individuals that were at the beginning of their aging process. Moreover, lack of such deposits in any other areas of the cerebellum document that in this period of aging, metabolism of APP and the increased concentration of A $\beta$ in the peripheral tissues preceded the same process in the cerebellum. Protein p53 was not detected in cerebella of those individuals suggesting that p53 did not participate in the formation of $A \beta$ plaques of such subependymoma localization. In addition, results obtained in the present study confirm the previous 


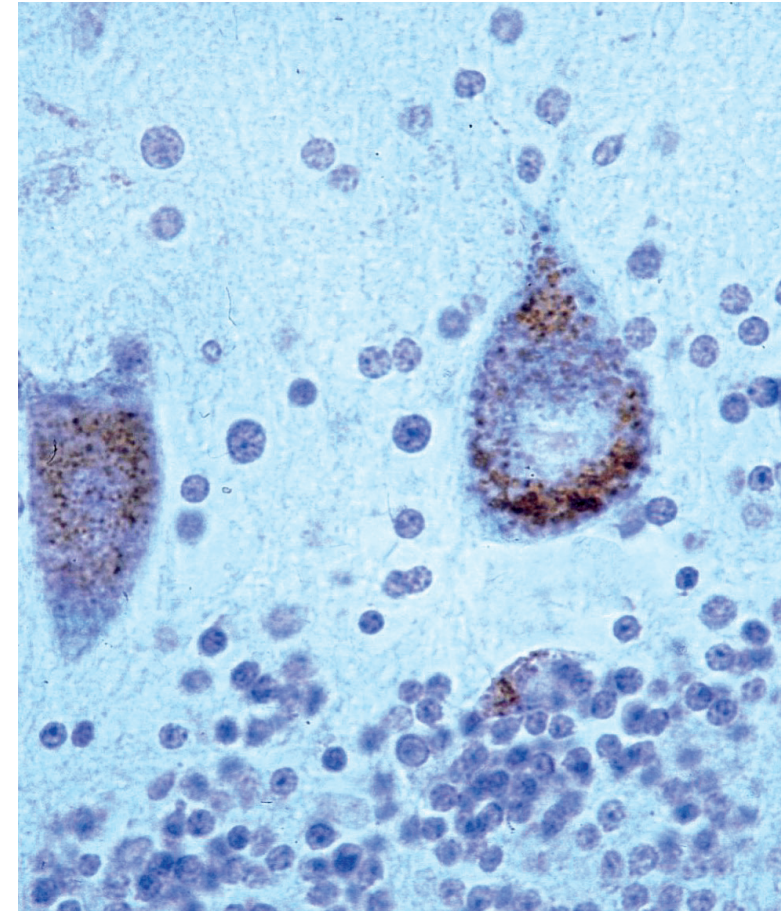

Fig. 4. p53 immuno-positive grains cumulated in the cytoplasm around the nucleus of Purkinje cells. Immunoreaction visualized with avidin-biotin-peroxidase system/DAB, counterstain with haematoxylin. Magnification $\times 400$.

observations that in other areas of the CNS, the efficiency of the blood-brain barrier may play an important role in the formation of $A B$ deposits, and suggest also that creation of such deposits is independent of the p53 local activity.

However, in the groups of older subjects (over 65 years of age), p53 was detected in numerous nerve cells of the cerebellar cortex. In some Purkinje cells we found this protein in cytoplasm but in others in the cell nucleus.

In the normal post mitotic cell as nerve cells are, the concentration of $\mathrm{p} 53$ protein is generally below the detection level of immunohistochemical methods.

Nevertheless, in all such cells endoplasmic reticulum (ER) is responsible for the synthesis and folding of different proteins including p53 which are entering the secretory/tertiary pathway. Many post-translational modifications that ensure protein function occur in this organelle $[9,17]$.

A variety of physiological perturbations can interfere with processes of protein folding in the ER lumen, leading to the unfolded or misfolded protein accumu-

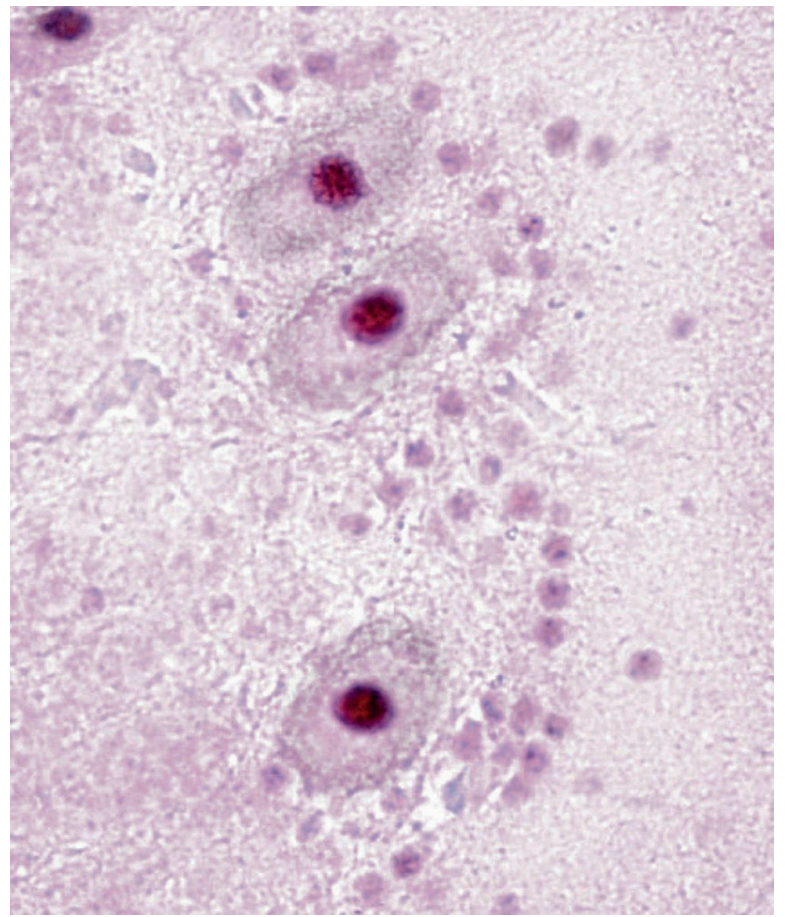

Fig. 5. p53 detected in the nucleus of Purkinje cells of the cerebellum. Pedestrian 75 years of age. Immunoreaction visualized with avidin-biotin/ alkaline phosphatase conjugate/AS/TR. Magnification $\times 400$.

lation, which is called "ER stress". This stress triggers and activates an adaptive reaction, termed unfolded protein response (UPR) [22].

The protein $\mathrm{p} 53$ is known to respond to a variety of cellular distress signals. In response to DNA damage the increased concentration of p53 may induce cell cycle arrest and apoptosis [10,12,15]. The "ER stress" was observed as the first step of $\mathrm{p} 53$ reaction in the cytoplasm of cerebellar neurons of our aging subjects.

The next step of $\mathrm{p} 53$ reaction in cerebella neurons was the accumulation of p53 in the nucleus of the nerve cells that undergo degeneration. The involvement of $\mathrm{p} 53$ in neurodegenerative processes has been previously demonstrated following ischemia and different excitotoxic insults $[5,19,37]$. Post-transcriptional modification can alter p53 tertiary structure and prevent it from binding to specific DNA structures [38].

It is known that p53 can induce either cell-cycle arrest or apoptosis through transcriptional regulation of several genes. However, p53 can induce apoptosis through multiple mechanisms. Nuclear p53 can bind 
to DNA and activate proapoptotic gene expression; alternatively, cytoplasmic p53 can trigger transcription-independent apoptosis by directly interacting with $\mathrm{Bcl}-2$ family members [7]. It has been proposed that after specific death stimuli, posttranslational modification of p53 may regulate its subcellular localization. Phosphorylation and acetylation of $\mathrm{p} 53$ sequester p53 in the nucleus [1] whereas monoubiquitination of p53 leads to its nuclear export [16] or mitochondrial translocation. Movement of proteins between the nucleus and the cytoplasm may require interaction with the nuclear pore complex component [33].

Some proteins that shuttle between the nucleus and the cytosol independent of the nuclear pore complex may be controlled purely by their molecular size. Other nuclear proteins, especially those with larger molecular mass, require interaction with nuclear pore components and/or intermediate carriers to escape from the nucleus. The nuclear export receptor regulates nuclear export of specific proteins and p53 is one of them. However, in our study, accumulation of $\mathrm{p} 53$ in the cytoplasm precede the immuno-detection of this protein in the cell nucleus suggesting that p53 accumulated in the cytoplasmic compartments has some handicap to enter the cell nucleus.

The results of our present study show that $p 53$ immunopositive degenerating neurons were the source of $A \beta$ fibrillar material, which in the molecular layer of the cerebellum created diffuse $A \beta$ plaques of extraordinary shapes. However, neither $A \beta$ nor p53 appear universal markers for aging of the nerve tissue because in approximately $50 \%$ of our aging individuals both proteins were not found in studied cerebellar sections.

In conclusion, all results document that p53 protein is involved in degeneration of cerebellar neurons thus participating also in the amyloidogenic process of the aging cerebellum.

\section{Disclosure}

Authors report no conflict of interest.

\section{References}

1. Appella E, Anderson CW. Posttranslational modifications and activation of p53 by genotoxic stressors. Eur I Biochem 2001; 268: $2764-2772$.
2. Armstrong RA. Laminar distribution of $\beta$-amyloid (AB) peptide deposits in the frontal lobe in familial and sporadic Alzheimer's disease. Folia Neuropathol 2015; 53: 15-23.

3. Blennow K, Hampel H. CSF markers for incipient Alzheimer's disease. Lancet Neurol 2003; 2: 605-613.

4. Buckner RL, Andrews-Hanna JR, Schacter DL. The brain's default network: anatomy, function, and relevance to disease. Ann NY Acad Sci 2008; 1124: 1-38.

5. Cenini G, Sultana R, Memo M, Butterfield DA. Elevated levels of pro-apoptotic $\mathrm{p} 53$ and its oxidative modification by the lipid peroxidation product, HNE, in brain from subjects with amnestic mild cognitive impairment and Alzheimer's disease. J Cell Mol Med 2008; 12: 987-994.

6. Chhatwal JP, Sperling RA. Functional MRI of mnemonic networks across the spectrum of normal aging, mild cognitive impairment, and Alzheimer's disease. J Alzheimers Dis 2012; 31 (Suppl 3): S155-S167.

7. ChipukJE, Bouchier-Hayes L, Kuwana T, Newmeyer DD, Green DR. PUMA couples the nuclear and cytoplasmic proapoptopic function of p53. Science 2005; 309: 1732-1735.

8. Chol SM. Movement disorders following cerebrovascular lesions in cerebellar circuits. J Mov Disord 2016; 9: 80-88.

9. Denzel A, Molinari M, Trigueros C, Martin JE, Velmurgan S, Brown S, Stamp G, Owen MJ. Early postnatal death and motor disorders in mice congenitally deficient in calnexin expression. Mol Cell Biol 2002; 22: 7398-7404.

10. Glaccia AJ, Kastan MB. The complexity of p53 modulation: emerging patterns from divergent signals. Genes Dev 1998; 12: 2973-2983.

11. Grimaldi G, Manto M. Topography of cerebellar deficits in humans. Cerebellum 2012; 11: 336-351.

12. Ko LJ, Prives C. p53: puzzle and paradigm. Gene Dev 1996; 10: 1054-1072.

13. Kramer A, Challen GA. The epigenetic basis of hemetopoietic stem cell aging. Semin Hematol 2017; 54: 19-24.

14. Lanni C, Racchi M, Mazzini G, Ranzenigo A, Polotti R, Sinforiani E, Olivari L, Barcikowska M, Styczynska M, Kuznicki J, Szybinska A Govoni S, Memo M, Uberti D. Conformationally altered p53: a novel Alzheimer's disease marker? Mol Psychiatry 2008; 13: 641-647.

15. Levine AJ. p53, the cellular gatekeeper for growth and division. Cell 1997; 88: 323-331.

16. Li M, Brooks CL, Wu-Baer F, Chen D, Baer R, Gu W. Monoversus polyubiquitination : differential control of p53 fate by Mdm2. Science 2003; 302: 1972-1975.

17. Luo S, Mao C, Lee B, Lee AS. GRP78/BiP is required for cell proliferation and protecting the inner cell mass from apoptosis during early mouse embryonic development. Mol Cell Biol 2006; 26: 5688-5697.

18. Matthews PM, Filippini N, Douaud G. Brain structural and functional connectivity and the progression of neuropathology in Alzheimer's disease. J Alzheimers Dis 2013; 33 (Suppl 1): S163-S172.

19. McGahan L, Hakim AM, Robertson GS. Hippocampal Myc and p53 expression following transient global ischemia. Brain Res Mol Brain Res 1998; 56: 133-145. 
20. Middleton FA, Strick PL. Anatomical evidence for cerebellar and basal ganglia involvement in higher cognitive function. Science 1994; 266: 458-461.

21. Mori F, Okada KI, Nomura T, Kobayashi Y. The pedunculopontine tegmental nucleus as a motor and cognitive interface between the cerebellum and basal ganglia. Front Neuroanat 2016; 10: 109.

22. Ni M, Lee AS. ER chaperones in mammalian development and human diseases. FEBS Lett 2007; 581: 3641-3651.

23. Rea IM, Dellet M, Mills KI. Living long and aging well is epigenetics the missing link between nature and nurture? Biogerontology 2016; 17: 33-54

24. Schmahmann JD, Caplan D. Cognition, emotion and the cerebellum. Brain 2006; 129: 290-292.

25. Schmahmann JD, Weilburg JB, Sherman JC. The neuropsychiatry of the cerebellum - insights from the clinic. Cerebellum 2007; 6: 254-267.

26. Schmahmann JD. Dysmetria of thought: clinical consequences of cerebellar dysfunction on cognition and affect. Trends Cogn Sci 1998; 2: 362-371.

27. Schmahmann JD. From movement to thought: anatomic substrates of the cerebellar contribution to cognitive processing. Hum Brain Mapp 1996; 4: 174-198.

28. Sheline YI, Raichle ME, Snyder AZ, Morris JC, Head D, Wang S, Mintun MA. Amyloid plaques disrupt resting state default mode network connectivity in cognitively normal elderly. Biol Psychiatry 2010; 67: 584-587.

29. Sokolov AA, Miall RC, Ivry RB. The cerebellum adaptive predic tion for movement and cognition. Trends Cogn Sci 2017; 21 313-332.

30. Steininger SC, Liu X, Gietl A, Wyss M, Schreiner S, Gruber E, Treyer V, Kälin A, Leh S, Buck A, Nitsch RM, Prüssmann KP, Hock C, Unschuld PG. Cortical amyloid beta in cognitively normal elderly adults is associated with decreased network efficiency within the cerebro-cerebellar system. Front Aging Neurosci 2014; 6: 52.

31. Stoodley CJ, Schmahmann JD. Evidence for topographic organization in the cerebellum of motor control versus cognitive and affective processing. Cortex 2010; 46: 831-844.

32. Stoodley CJ, Valera EM, Schmahmann JD. Functional topography of the cerebellum for motor and cognitive tasks: an fMR study. Neuroimage 2012; 59: 1560-1570.

33. Talcott B, Moore MS. Getting across the nuclear pore complex. Trends Cell Biol 1999; 9: 312-318.

34. Taormina G, Mirisola MG. Longevity epigenetic and biomolecular aspects. Biomol Concepts 2015; 6: 105-117.

35. Thach WT, Goodkin HP, Keating JG. The cerebellum and the adaptive coordination of movement. Annu Rev Neurosci 1992; 15: 403-442.

36. Thal LJ, Kantarci K, Reiman EM, Klunk WE, Weiner MW, Zetterberg H, Galasko D, Pratico D, Griffin S, Schenk D, Siemers E. The role of biomarkers in clinical trials for Alzheimer's disease. Alzheimer Dis Assoc Disord 2006; 20: 6-15.

37. Uberti D, Belloni M, Grilli M, Spano P, Memo M. Induction of tumour-suppressor phosphoprotein p53 in the apoptosis of cultured rat cerebellar neurons triggered by excitatory amino acids. Eur J Neurosci 1998; 10: 246-254.
38. Uberti D, Lanni C, Carsana T, Francisconi S, Missale C, Racchi M, Govoni S, Memo M. Identification of a mutant-like conformation of p53 in fibroblasts from sporadic Alzheimer's disease patients. Neurobiol Aging 2006; 27: 1193-1201. 